\title{
Nitrate supply and demand in the mixed layer of the ocean
}

\author{
Trevor Platt ${ }^{1, *}$, Shubha Sathyendranath ${ }^{1,2}$, Andrew M. Edwards ${ }^{1,2}$, \\ David S. Broomhead ${ }^{3}$, Osvaldo Ulloa ${ }^{4}$ \\ ${ }^{1}$ Biological Oceanography Section, Bedford Institute of Oceanography, Box 1006, Dartmouth, Nova Scotia B2Y 4A2, Canada \\ ${ }^{2}$ Department of Oceanography, Dalhousie University, Halifax, Nova Scotia B3H 4J1, Canada \\ ${ }^{3}$ Department of Mathematics, University of Manchester Institute of Science and Technology, PO Box 88, \\ Manchester M60 1QD, United Kingdom \\ ${ }^{4}$ Centro de Investigación Oceanográfica en el Pacífico sur-Oriental and Departamento de Oceanografía, \\ Universidad de Concepción, Casilla 160-C, Concepción, Chile
}

\begin{abstract}
We define a new dimensionless number, $S$, to be the ratio of nitrogen supply to nitrogen demand of new primary production in the pelagic ecosystem. When $S>1$, we expect high-nutrient, low-chlorophyll (HNLC) conditions. Using the results of a new model of nitrogen input and consumption for the mixed layer of the ocean, we calculate $S$ for selected oceanic regimes. Those generally accepted to be HNLC are characterised by $S>1$. The bio-optical terms in this model (specific absorption of pigments, parameters of the light-saturation curve) are known to respond to addition of iron. Using these known responses, we recalculated the expected value of $S$ under hypothetical enrichments of the selected regimes with iron. In each case, the magnitude of $S$ was reduced, but not always below unity. The maximum value of chlorophyll biomass that can be sustained in a given mixed layer may be calculated from consideration of either the bio-optics or the nitrogen supply. The maximum realised biomass will be the smaller of these 2 estimates.
\end{abstract}

KEY WORDS: High-nutrient low-chlorophyll $\cdot$ HNLC $\cdot$ Iron fertilisation · Plankton models $\cdot$ IronEx

\section{INTRODUCTION}

Among the issues that have captured the interest of ocean biogeochemists during the past decade, the significance of areas with high residual nutrients (in particular nitrate) and low chlorophyll concentration (the so-called HNLC regime) is prominent (Chisholm \& Morel 1991). It has been inferred that such systems are, in some way, biologically limited (Martin et al. 1990b): otherwise, the nutrients would be consumed, with a concomitant increase in phytoplankton biomass (as indexed by chlorophyll concentration). Iron, an essential element for autotrophic physiology, has been identified as a potentially limiting resource (Martin \& Fitzwater 1988), with the corollary that addition of iron to the ocean would enhance photosynthesis by phytoplankton (Martin et al. 1990a, Coale et al. 1996), leading to complete utilisation of the ambient nitrate. Here, we show that HNLC regimes need not be considered as anomalous marine ecosystems; rather, they should be seen as elements of a continuum in which the biological dynamics are controlled by the ratio of nutrient supply to the nutrient demand of the local primary production, which is determined by the bio-optical characteristics of the pelagic ecosystem. We introduce a new dimensionless number, $S$, that captures the dynamics and diagnoses whether a given region will be HNLC, either in its pristine condition or after treatment with iron. 
That the nitrate is not exhausted (by definition) in HNLC regions is an indication that it is resupplied, if not continuously then at least fast enough (on the average) to exceed the demands of new production (Dugdale 1967, Platt et al. 1989). An important mechanism for nutrient resupply to the upper mixed layer is entrainment through deepening of the layer (Gardner et al. 1993), for example following passage of a storm system (or a mesoscale eddy). Against this background, we constructed and examined (Platt et al. 2003) a simple, analytic model (Fig. 1) of phytoplankton and nutrients in a mixed layer whose depth is modulated intermittently.

\section{MODEL DESCRIPTION}

The model is an idealised representation of dynamics in the pelagic ecosystem. Below the mixed layer, nitrate concentration $\left(N_{d}\right)$ is fixed, and the biomass of phytoplankton is zero. When the mixed layer deepens, the entrained water replenishes some or all of the nitrate consumed by growth and dilutes the biomass, increasing the optical transparency. When the mixed layer shallows, nitrate and biomass are lost from it: biomass thus lost cannot re-enter the mixed layer. The intrinsic time step of the model is $1 \mathrm{~d}$. In the mixed layer, the concentrations of chlorophyll and nitrate are $B(t)$ and $N(t)$, respectively, evaluated at the start of Day $t$. The mixed-layer depth $Z_{m}(t)$ is perturbed intermittently (not every day) by step changes of common amplitude (a) around a mean depth $\left(Z_{m}^{0}\right)$, with such changes occurring at the end of the day.

The increase in mixed-layer chlorophyll through photosynthesis on a given day is:

$$
\frac{P(t)}{\chi Z_{m}(t)}=\frac{P_{m}^{B} B(t) D}{\chi \theta(t)}\left[f\left(I_{*}{ }^{m}\right)-f\left(I_{*}{ }^{m} \mathrm{e}^{-\theta(t)}\right)\right]
$$

where we have the primary production $P(t)$ within the mixed layer, the daylength $D$, a known function (Platt \& Sathyendranath 1993) $f(\cdot)$ of the normalised noon irradiance $I_{*}^{m}$ (the noon irradiance $I_{0}^{m}$ scaled by the ratio of the photosynthesis parameters $\alpha^{B} / P_{m}^{B}$, where $\alpha^{B}$ is the initial slope of the photosynthesis-irradiance curve and $P_{m}^{B}$ is the specific production at saturating light), the ratio of carbon to chlorophyll $\chi$, and the optical thickness of the mixed layer $\theta(t)=Z_{m}(t) K(t)$, where $K(t)=K_{W}+k_{c} B(t)$ is the diffuse vertical attenuation coefficient, with $K_{W}$ the attenuation due to water and $k_{c}$ the specific attenuation coefficient of chlorophyll.

In the simplest case, the loss term for phytoplankton biomass can be taken as a constant fraction $(\lambda)$ of the biomass. We have solved this system, and full details

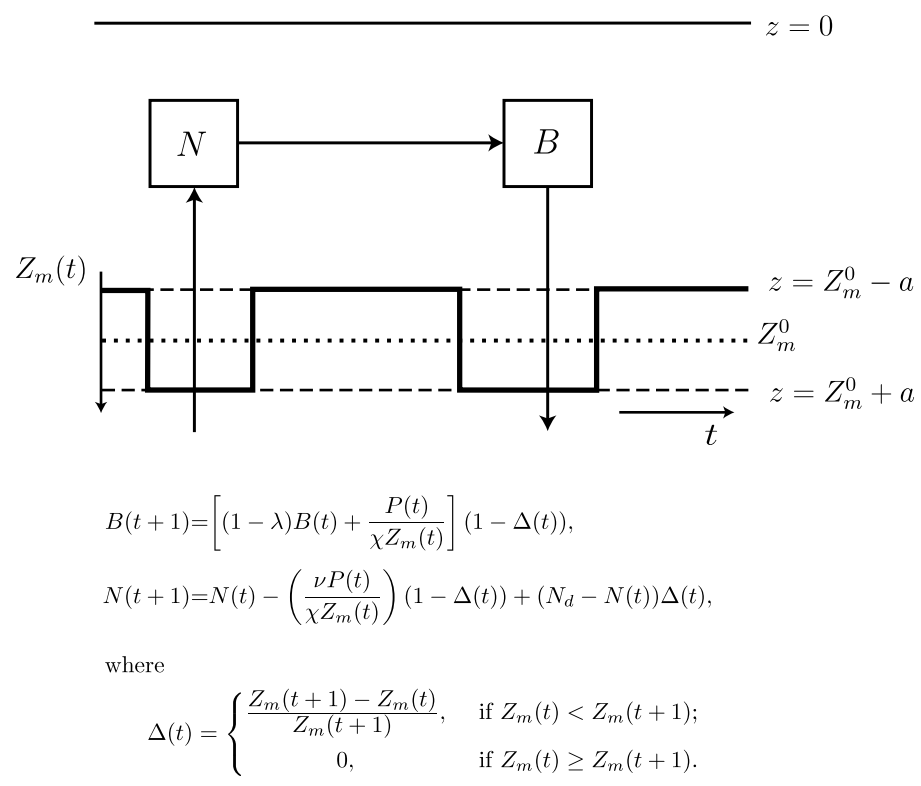

Fig. 1. Schematic of basic model, with governing equations Nitrate, $N$, is supplied from the reservoir (concentration $N_{d}$ ) below the mixed layer and converted to biomass, $B$, of phytoplankton. Depth $z$ is positive downwards. Mixed-layer depth $Z_{m}(t)$, is modulated intermittently about $Z_{m}^{0}$ in a series of steps of common amplitude $2 a$ but variable timestep. Time $t$ increases in steps of $1 \mathrm{~d}$. The daily primary production in the mixed layer is $P(t)$. A fraction $(\lambda)$ of the biomass is lost each day from the layer. The stoichiometric equivalents of nitrogen and carbon, relative to chlorophyll, are $v$ and $\chi$ respectively. The quantity $\Delta(t)$, which is zero except when the mixed layer deepens, accounts for the redistribution of material by vertical mixing

are presented elsewhere (Platt et al. 2003). The solutions lead to explicit expressions for the bounds on residual nitrate and biomass. The biomass will converge to a stable, globally attracting value set by the mixed-layer depth, the loss term and the bio-optical properties of phytoplankton (i.e. for a given parameter set and constant mixed-layer depth, all biomass simulations will converge to the same biomass value, regardless of the initial biomass value used). The maximum attainable biomass $\left(B_{u}\right)$ will be the value to which it converges at the shallow mixed-layer depth (see Appendix 1). This maximum will be attained provided that nitrogen supply is sufficient; beyond that, increased nitrogen supply will have no effect on the upper bound for biomass, but will lead to residual nitrate in the mixed layer. The lower bound for the residual nitrate concentration $\left(N_{r}\right)$ will be higher for higher nitrate concentration below the mixed layer $\left(N_{d}\right)$, smaller maximum biomass, and shorter intervals between storms (see Appendix 1). 

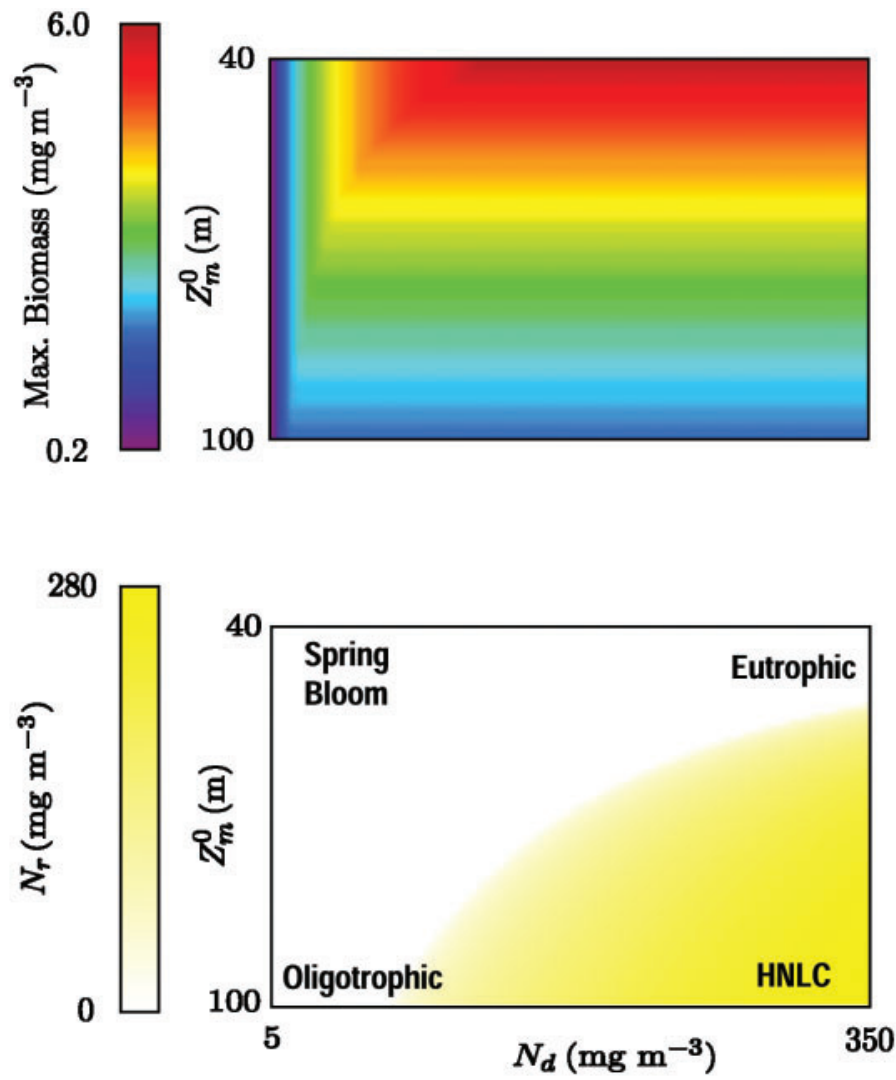

Fig. 2. Computed maximum biomass $\left(B_{u}\right.$ or $\left.B_{s p}\right)$ and minimum residual nitrate $\left(N_{r}\right)$ computed using the model, for a range of $Z_{m}^{0}$ and $N_{d}$ values. Parameters were fixed at the following realistic values: $\chi=90 \mathrm{mgC}(\mathrm{mg} \mathrm{chl})^{-1} ; \lambda=0.6$ (dimensionless); $v=8.8 \mathrm{mgN}\left(\mathrm{mg} \mathrm{chl}^{-1} ; \mathrm{a}=25 \mathrm{~m} ; D=13 \mathrm{~h}_{;} I_{*}^{m}=10\right.$ (dimensionless); $k_{C}=0.05 \mathrm{~m}^{2}(\mathrm{mg} \mathrm{chl})^{-1} ; k_{W}=0.043 \mathrm{~m}^{-1} ; P_{m}^{B}=10 \mathrm{mgC}$ $(\mathrm{mg} \mathrm{chl})^{-1} \mathrm{~h}^{-1}$; and $T=7 \mathrm{~d}$. Various environments, such as oligotrophic, eutrophic, or high-nutrient, low-chlorophyll regions, and phenomena such as the spring bloom, can result from differences in forcing (mixed-layer depth and concentration of nitrogen below mixed layer) for phytoplankton populations with identical properties. (See 'Model description' for definition of parameters)

Thus, the residual nitrate in the ocean is set by the balance between supply and demand for this nutrient: both of these terms are under the influence of physical forcing. The nitrate-chlorophyll plane may be seen as a bidirectional continuum in which the HNLC regimes occupy, at most, 1 quadrant (Fig. 2). They will occur in the appropriate region of parameter space, even when no essential growth factor is lacking. Of course, unavailability of a substrate critical for growth may constitute a condition favouring high levels of unconsumed nitrate (through suppression of nitrate demand), but such unavailability does not appear to be a necessary condition for HNLC.

\section{RESULTS}

\section{A new dimensionless number}

Generally, HNLC conditions should occur whenever and wherever nitrate is resupplied at a rate exceeding the demands of local new production. We can express this condition in the form of a dimensionless number, $S$, calculated (conservatively) as $S=$ (minimum nitrate nitrogen supply rate)/(maximum nitrate equivalent of new production), where both quantities are expressed per unit volume in the mixed layer. If $T$ is the maximum interval between deepening events and $2 a$ is the typical excursion of the mixed-layer depth following passage of a storm system, the numerator will be $2 a N_{d} /\left[\left(Z_{m}^{0}+a\right) T\right]$, the entrained nitrogen $2 a N_{d}$ being distributed after deepening over a layer of thickness $\left(Z_{m}^{0}+a\right)$ every $T$ days. The denominator $P v /\left[\left(Z_{m}^{0}-a\right) \chi\right]$ is the primary production $P$, calculated from Eq. (1) for the case where biomass is equal to the upper bound $B_{u}$ (which occurs when the mixed layer depth is $Z_{m}^{0}-a$ ), and converted to nitrogen units by the factor $v / \chi$, where $v$ is the ratio of nitrogen to chlorophyll in phytoplankton tissue. Then,

$$
S=\left(\frac{2 a N_{d}}{P T}\right)\left(\frac{Z_{m}^{0}-a}{Z_{m}^{0}+a}\right) \frac{\chi}{v}
$$

If $S>1$, we may anticipate HNLC conditions. This will tend to be the case for large excursions of the mixed-layer depth, low mixed-layer production, high nitrate concentrations at depth, and shorter intervals between storms. Generally, we anticipate that if $T$ is large, the biomass will tend to be limited by nutrient exhaustion, whereas for small $T$, biomass will tend to be limited by dilution, leaving residual, unconsumed nutrients.

\section{Application to oceanic regimes}

We calculated $N_{r}$ and $S$ for various oceanic regions (Table 1). To achieve this, we adjusted the value of $\lambda$ for each region such that the computed value of $B_{u}$ (see Appendix 1) agreed with the observations. Eq. (1) then gave the primary production $P$, which was used in Eq. (2) to give $S$. It is also possible (Platt et al. 2003) to calculate $N_{r}$ from Eq. (A1) (see Appendix 1). The magnitudes of $S$ are consistent with conventional designation of the regions as HNLC or not, illustrating the utility of the dimensionless index as a diagnostic.

In the case of the Sargasso Sea, the calculated residual nitrate was negative for both spring and summer 
conditions. This non-physical result implies that, although the values for $B_{u}$ are possible from a bio-optical perspective, the supply of nitrate from below may be insufficient to sustain such values. In spring, the observed biomass can be reached temporarily, only because the pre-bloom nitrate concentration in the mixed layer is sufficiently high; the spring maximum $B_{s p}$ (see Appendix 1) is $3.82 \mathrm{mg} \mathrm{chl} \mathrm{m}^{-3}$. For the case of summer in the Sargasso Sea, the bio-optical maximum in biomass can be reached only in those years for which the vertical mixing is greater than assumed here. The values of $B_{u}$ for both spring and summer in the Sargasso Sea are transient maxima and will erode as soon as the initial nitrate stock in the mixed layer becomes exhausted. In Table 1, the values in parentheses correspond to the maximum biomass $\left(B_{N}\right.$ in Appendix 1) that could be maintained by the given nitrate supply.

It is now of interest to investigate how $S$ and $N_{r}$ might change under the addition of iron in those regions characterised as HNLC. In the context of our model (Eq. 1), mixed-layer primary production could be enhanced through modification of the normalised photosynthesis parameters or the specific attenuation coefficient (Platt et al. 2003). From the results of experiments conducted in the equatorial Pacific (Lindley \& Barber 1998), we calculated a $40 \%$ increase in $\alpha^{B}$ and a $27 \%$ decrease in $k_{C}$ for the water enriched with iron compared with the values for the control. A corresponding decrease in $\chi$ of $53 \%$ has been observed (Landry et al. 2000). For the Southern Ocean, using the changes in $K$ and $B$ during the course of the iron-enrichment experiment (Gall et al. 2001), we deduced that $k_{c}$ decreased by $56 \%$ from 0.072 to $0.032 \mathrm{~m}^{2}(\mathrm{mg} \mathrm{chl})^{-1}$ following addition of iron. We used values for the photosynthesis parameters reported for the Southern Ocean (Mitchell et al. 1991). The value of the assimilation number $P_{m}^{B}$ following addition of iron was estimated by matching the calculated production to the observations, requiring an increase in $P_{m}^{B}$ of $68 \%$.

Using these results as a basis, we can now estimate the magnitudes of $S$ under addition of iron for the field experiments IronEx-I, IronEx-II and the Southern Ocean Iron RElease Experiment (SOIREE) (Martin et al. 1993, Coale et al. 1996, Boyd et al. 2000 respectively). In each case, there is a reduction in $S$, as expected, but only in the case of IronEx-II does $S$ fall below unity and $N_{r}$ below zero. However, $B_{N}>B_{u i}$ therefore, $B_{u}$ can be attained, but not sustained unless nitrate supply is increased (so that $N_{r}>0$ ). On the other hand, the maximum observed biomass during SOIREE is shown to be sustainable $\left(S>1\right.$ and $N_{r}>0$ ), as was observed to be the case because the bloom persisted for many weeks.
One of the uses of this analysis is to deduce $\lambda$, which is difficult to measure directly. In the Sargasso Sea and in the equatorial Pacific the values lie in the range from about 30 to $40 \%$. For the Southern Ocean $\lambda$ is significantly lower, at $15 \%$. Following iron enrichment, inferred values of $\lambda$ increased in all 3 experiments (Table 1), reflecting an increase in either grazing pressure or sinking rates or both. The retrieved $\lambda$ is greater for IronEx-I than that for IronEx-II, consistent with observations (Lindley \& Barber 1998). Thus, although the model is very simple, it is able to capture the principal features of the major iron-manipulation experiments. Furthermore, the model can be used to analyse changes to the 'topdown' control on the phytoplankton upon addition of iron to the system.

\section{DISCUSSION}

Episodic increase in mixed-layer depth in response to changes in wind stress is well known (Sakshaug et al. 1991). It is also known that mixed-layer depths are changing in the world ocean on decadal time scales. In HNLC regimes, high and intermittent wind stress, and a tendency for a net supply of nutrients to the surface ocean, are often salient characteristics of regional meteorological forcing (Mitchell et al. 1991, Sakshaug et al. 1991). To the extent that weather patterns (in particular the distribution of wind-stress curl and the frequency and intensity of storms) may be modified through the suite of processes collectively known as climate change, we could expect the world distribution of HNLC regimes to change accordingly.

We have used a simple representation of hydrodynamics, such that the nitrate supply rate in our $S$ calculation is determined by the extent and frequency of mixed-layer deepening. However, other mechanisms of nitrate supply could be considered, such as a constant supply due to wind-driven upwelling, for which a value of $S$ could again be calculated. In further work (Edwards et al. unpubl. work) we have considered more explicitly the temporal dynamics of the mixed layer. Moreover, because the choice of closure term (loss term of the highest trophic level modelled) has often been found to strongly influence the dynamics of models (Steele \& Henderson 1992, Edwards \& Yool 2000), we have also investigated the use of a quadratic loss term in place of the linear loss term (Edwards et al. unpubl. work).

Because photosynthesis lowers the partial pressure of carbon dioxide in the surface layers of the ocean, fertilisation of HNLC regions with iron has been advanced as a possible mechanism for mitigation of 
Table 1. Input parameters and computed model outputs for selected oceanographic regions and conditions. $Z_{m}^{0}$ : mean depth (m) of mixed layer; $a$ : amplitude of oscillation of mixed-layer depth, $\mathrm{m}_{i} k_{c}$ : biomass-specific vertical attenuation coefficient for photo-

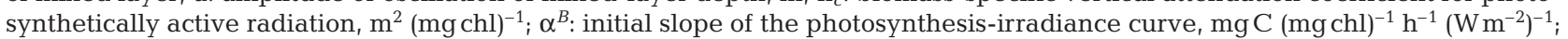
$P_{m}^{B}$ : specific production at saturating light $\left(\mathrm{mg} \mathrm{C} \mathrm{mg}^{-1} \mathrm{chl}\right) \mathrm{h}^{-1} ; \lambda$ : biomass loss (dimensionless); $\chi$ : carbon to chlorophyll ratio, mg C $(\mathrm{mg} \mathrm{chl})^{-1} ; B_{u}$ : maximum biomass, $\mathrm{mg} \mathrm{chl} \mathrm{m}^{-3} ; N_{r}$ : residual nitrate, $\mathrm{mgN} \mathrm{m}^{-3}$. Quantity $S$ (ratio of $N$ supply to $N$ demand of new primary production) is dimensionless. Published parameter values used whenever available. For SOIREE, photosynthetic parameters were adjusted in primary production model to match observed production per unit biomass. Daylength, $D$, and noon irradiance, $I_{0}^{m}$, were computed using geographic location and season and a clear-sky model, yielding values of $12.7 \mathrm{~h}$ and $324 \mathrm{~W} \mathrm{~m}^{-2}$ for Sargasso Sea spring, $13.2 \mathrm{~h}$ and $340 \mathrm{~W} \mathrm{~m}^{-2}$ for Sargasso Sea summer, $12 \mathrm{~h}$ and $350 \mathrm{~W} \mathrm{~m}^{-2}$ for the equatorial Pacific, and $16 \mathrm{~h}$ and $90 \mathrm{~W} \mathrm{~m}^{-2}$ for the Southern Ocean respectively. Remaining parameters were held constant for all locations: $K_{W}=0.042 \mathrm{~m}^{-1}$, $v=8.8 \mathrm{mgN}(\mathrm{mg} \mathrm{chl})^{-1}$ and $T=7 \mathrm{~d}$ (where $K_{W}=$ attenuation due to water, $v=$ ratio of $N$ to chlorophyll in phytoplankton tissue, and $T=$ maximum interval between deepening events). The loss term $\lambda$ was a free parameter, adjusted so that $B_{u}$ equalled the maximum reported values of biomass from literature. Values in parentheses correspond to the maximum biomass, $B_{N}$ (see 'Application to oceanic regimes'). $N_{r}$ and parameter $S$ were then computed using the input parameters. SOIREE: Southern Ocean Iron RElease Experiment

\begin{tabular}{|c|c|c|c|c|c|c|c|c|c|c|c|}
\hline \multirow{2}{*}{$\begin{array}{l}\text { Region and } \\
\text { condition }\end{array}$} & \multicolumn{8}{|c|}{ Input parameters (observed and inferred) } & \multicolumn{3}{|c|}{ Modelled outputs } \\
\hline & $Z_{m}^{0}$ & a & $N_{d}$ & $k_{c}$ & $\alpha^{B}$ & $P_{m}^{B}$ & $\lambda$ & $\chi$ & $B_{u}$ & $N_{r}$ & $S$ \\
\hline \multicolumn{12}{|c|}{ Sargasso Sea ${ }^{a}$} \\
\hline Spring & 55 & 15 & 56 & 0.05 & 0.140 & 6.2 & 0.40 & 50 & $2.98(1.64)$ & -199 & 0.33 \\
\hline Summer & 85 & 15 & 4.34 & 0.05 & 0.053 & 2.4 & 0.31 & 50 & $0.25(0.10)$ & -17 & 0.27 \\
\hline \multicolumn{12}{|c|}{ Equatorial Pacific ${ }^{\mathrm{b}}$} \\
\hline Typical & 50 & 20 & 112 & 0.037 & 0.060 & 6 & 0.29 & 150 & 0.24 & 98 & 15 \\
\hline IronEx-I ${ }^{c}$ & 50 & 20 & 112 & 0.027 & 0.084 & 6 & 0.68 & 70 & 0.57 & 41 & 2.7 \\
\hline IronEx-II ${ }^{\mathrm{c}}$ & 50 & 20 & 112 & 0.027 & 0.084 & 6 & 0.43 & 70 & $2.98(4.15)$ & -133 & 0.81 \\
\hline \multicolumn{12}{|c|}{ Southern Ocean ${ }^{\mathrm{d}}$} \\
\hline Typical & 65 & 8 & 350 & 0.072 & 0.276 & 1.1 & 0.15 & 90 & 0.26 & 335 & 32 \\
\hline SOIREE ${ }^{c}$ & 65 & 8 & 350 & 0.032 & 0.276 & 1.85 & 0.29 & 45 & 1.82 & 167 & 2.4 \\
\hline \multirow{2}{*}{\multicolumn{12}{|c|}{ 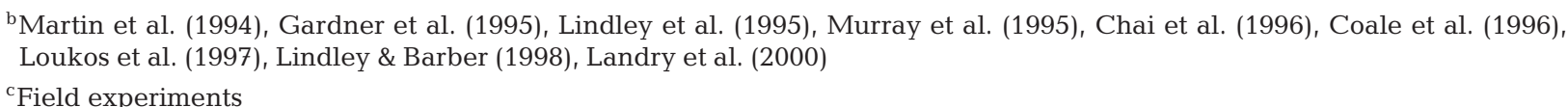 }} \\
\hline & & & & & & & & & & & \\
\hline \multicolumn{12}{|c|}{$\begin{array}{l}\text { dMitchell et al. (199 } \\
\text { dMeld experments }\end{array}$} \\
\hline
\end{tabular}

the anthropogenically enhanced greenhouse effect caused by increasing concentrations of carbon dioxide in the atmosphere (Martin et al. 1990a). The results presented here provide a framework within which the results of oceanographic expeditions to HNLC regions could be discussed and interpreted, especially with respect to their bearing on the issue of iron fertilisation. Our analysis shows that, although lack of a limiting resource (e.g. iron) may constitute a sufficient condition for occurrence of HNLC regions, it is not a necessary condition for their existence. Even when phytoplankton growth is stimulated by addition of iron, other bio-optical and physical factors may limit the evolution of biomass and nutrients in the mixed layer. Our results show that iron stimulation may be of only transient value, at least in some regions and under some conditions of physical forcing. Furthermore, the observed responses are achieved at the cost of changing the dominant phytoplankton population (as evidenced by the change in $k_{c}$ ), with unknown consequences to the integrity of the pelagic ecosystem if iron enrichment were pursued as a long-term strategy. Needless to say, any large-scale modification of the ocean ecosystem should be undertaken only with extreme caution.

Acknowledgements. This work was initiated while the authors were in residence at the Isaac Newton Institute for the Mathematical Sciences, Cambridge. We thank George White for his assistance. A.M.E. was supported by the Department of Fisheries and Oceans (Canada) through the Science Strategic Fund (project number 21778). O.U. was supported by the Chilean National Commission for Scientific and Technological Research (CONICYT), through the FONDAP Program, and by the Fundación Andes. This work is a contribution to the Canadian Surface-Ocean Lower Atmosphere Studies (SOLAS) programme. 
Appendix 1. Calculation of upper and lower bounds on biomass and nitrate respectively

\section{UPPER BOUNDS ON BIOMASS}

\section{Bio-optical maximum}

From the bio-optical point of view, using Eq. (1) and Fig. 1, the upper bound $B_{u}$ (Platt et al. 2003) is the solution of the equation

$$
\begin{aligned}
& B_{u}=(1-\lambda) B_{u} \\
& +\frac{P_{m}^{B} D B_{u}}{\chi\left(K_{W}+k_{c} B_{u}\right)\left(Z_{m}^{0}-a\right)}\left[f\left(I_{*}^{m}\right)-f\left(I_{*}^{m} \mathrm{e}^{-\left(K_{w}+k_{c} B_{u}\right)\left(Z_{m}^{0}-a\right)}\right)\right]
\end{aligned}
$$

This maximum biomass will be attained only if the mixed layer remains shallow for a sufficiently long time (because when the mixed layer deepens the biomass will be diluted). The value of $B_{u}$ is used to give the production necessary to calculate $S$, since for $S$ we require the maximum new production, which is the production when $B=B_{u}$. Eq. (A1) cannot be solved analytically to give $B_{u}$ explicitly as a function of the parameters (note how $B_{u}$ appears on the right-hand side), but in Platt et al. (2003) we give some insight into the dependence of $B_{u}$ on the parameters. This result is independent of nitrogen supply.

\section{Nutrient-limited maximum}

Initial supply: When we take the nitrogen supply into account, other limitations apply. The maximum possible biomass will occur when the deep nitrogen concentration $N_{d}$ is converted completely into chlorophyll. This could arise, for example, following deep winter-mixing when the initial nitrogen concentration in the mixed layer is equal to $N_{d}$ : it is the stereotypic case for the spring bloom, and we refer to this bound as $B_{s p}$. It is given by

$$
B_{s p}=\frac{N_{d}}{v}(1-\lambda)
$$

with the implication that the conversion was made in $1 \mathrm{~d}$ (upper limit). If the conversion took, say, $n$ days, the term $(1-\lambda)$ would be replaced by $(1-\lambda)^{n}$. This bound cannot be sustained without an adequate resupply of nitrogen, failing which the estimate of residual nitrate $N_{r}$ in the mixed layer will be negative.

Episodic supply: The spring-bloom case is an extreme one, for which the surface and deep nitrate concentrations are the same. More typical is the case where mixed-layer nitrate $N(t)<N_{d}$ and nitrate is resupplied through entrainment by deepening of the mixed layer. For an excursion of the mixed layer (2a), the entrained nitrate is $2 a N_{d}$ redistributed over a depth interval, $Z_{m}^{0}+a$, to give a final concentration of $2 a N_{d} /\left(Z_{m}^{0}+a\right)$. Then, after complete conversion of the nitrate to chlorophyll, we find $B_{N}$, the maximum nitrogen-supply-limited biomass, is

$$
B_{N}=\frac{2 a N_{d}}{v\left(Z_{m}^{0}+a\right)}(1-\lambda)
$$

Thus, we find the upper bounds on the biomass by considering either the nitrate supply or the bio-optical properties. The maximum realised biomass will be whichever of the bounds is the smallest, depending on the conditions. The maximum observed biomass would be the lower of the bio-optical or the nitrate-limited maxima.

\section{LOWER BOUND ON NITRATE}

The lower bound, $N_{r}$, on the nitrate is given by Platt et al. (2003):

$$
N_{r}=N_{d}-v B_{u}\left[1+\lambda\left(\frac{1}{G\left(1-G^{1 / T}\right)}-1\right)\right]
$$

where $G=\left(Z_{m}^{0}-\mathrm{a}\right) /\left(Z_{m}^{0}+\mathrm{a}\right)$.

\section{LITERATURE CITED}

Boyd PW, Watson AJ, Law CS, Abraham ER and 31 others (2000) A mesoscale phytoplankton bloom in the polar Southern Ocean stimulated by iron fertilization. Nature 407:695-702

Chai F, Lindley ST, Barber RT (1996) Origin and maintenance of a high nitrate condition in the equatorial Pacific. DeepSea Res II 43:1031-1064

Chisholm SW, Morel FMM (eds) (1991) What controls phytoplankton production in nutrient-rich areas of the open sea? Limnol Oceanogr 36:1507-1565

Coale KH, Johnson KS, Fitzwater SE, Gordon RM and 15 others (1996) A massive phytoplankton bloom induced by an ecosystem-scale iron fertilization experiment in the equatorial Pacific Ocean. Nature 383:495-501

Dugdale RC (1967) Nutrient limitation in the sea: dynamics, identification, and significance. Limnol Oceanogr 12: 685-695

Edwards AM, Yool A (2000) The role of higher predation in plankton population models. J Plankton Res 22:1085-1112

Gall MP, Strzepek R, Maldonado M, Boyd PW (2001) Phytoplankton processes. Part 2: Rates of primary production and factors controlling algal growth during the Southern
Ocean Iron RElease Experiment (SOIREE). Deep-Sea Res II 48:2571-2590

Gardner WD, Walsh ID, Richardson MJ (1993) Biophysical forcing of particle production and distribution during a spring bloom in the North Atlantic. Deep-Sea Res II 40: 171-195

Gardner WD, Chung SP, Richardson MJ, Walsh ID (1995) The oceanic mixed-layer pump. Deep-Sea Res II 42:757-775

Lancelot C, Hannon E, Becquevort S, Veth C, De Baar HJW (2000) Modeling phytoplankton blooms and carbon export production in the Southern Ocean: dominant controls by light and iron in the Atlantic sector in Austral spring 1992. Deep-Sea Res II 47:1621-1662

Landry MR, Ondrusek ME, Tanner SJ, Brown SL, Constantinou J, Bidigare RR, Coale KH, Fitzwater S (2000) Biological response to iron fertilization in the eastern equatorial Pacific (IronEx II). I. Microplankton community abundances and biomass. Mar Ecol Prog Ser 201:27-42

Lindley ST, Barber RT (1998) Phytoplankton response to natural and experimental iron addition. Deep-Sea Res II 45:1135-1150

Lindley ST, Bidigare RR, Barber RT (1995) Phytoplankton photosynthesis parameters along $140^{\circ} \mathrm{W}$ in the equatorial Pacific. Deep-Sea Res II 42:441-463 
Loukos H, Frost B, Harrison DE, Murray JW (1997) An ecosystem model with iron limitation of primary production in the equatorial Pacific at $140^{\circ} \mathrm{W}$. Deep-Sea Res II 44: 2221-2249

Martin JH, Fitzwater SE (1988) Iron deficiency limits phytoplankton growth in the north-east Pacific subarctic. Nature 331:341-343

Martin JH, Fitzwater SE, Gordon RM (1990a) Iron deficiency limits phytoplankton growth in Antarctic waters. Global Biogeochem Cycles 4:5-12

Martin JH, Gordon RM, Fitzwater SE (1990b) Iron in Antarctic waters. Nature 345:156-158

Martin JH, Coale KH, Johnson KS, Fitzwater SE and 40 others (1994) Testing the iron hypothesis in ecosystems of the equatorial Pacific Ocean. Nature 371:123-129

McGillicuddy DJ Jr, Robinson AR (1997) Eddy-induced nutrient supply and new production in the Sargasso Sea. DeepSea Res I 44:1427-1450

McGillicuddy DJ Jr, McCarthy JJ, Robinson AR (1995) Coupled physical and biological modeling of the spring bloom in the North Atlantic (I): model formulation and one dimensional bloom process. Deep-Sea Res I 42:1313-1357

Mitchell BG, Brody EA, Holm-Hansen O, McClain C, Bishop, J (1991) Light limitation of phytoplankton biomass and macronutrient utilization in the Southern Ocean. Limnol Oceanogr 36:1662-1677

Murray JW, Johnson E, Garside C (1995) A U.S. JGOFS pro-

Editorial responsibility: Otto Kinne (Editor),

Oldendorf/Luhe, Germany cess study in the equatorial Pacific (EqPac): Introduction. Deep-Sea Res II 42:275-293

Platt T, Sathyendranath S (1993) Estimators of primary production for interpretation of remotely sensed data on ocean color. J Geophys Res 98:14561-14576

Platt T, Harrison WG, Lewis MR, Li WKW, Sathyendranath S, Smith RE, Vézina AF (1989) Biological production of the oceans: the case for a consensus. Mar Ecol Prog Ser 52: $77-88$

Platt T, Sathyendranath S, Ravindran P (1990) Primary production by phytoplankton: analytic solutions for daily rates per unit area of water surface. Proc R Soc Lond Ser B 241: 101-111

Platt T, Sathyendranath S, Ulloa O, Harrison WG, Hoepffner N, Goes J (1992) Nutrient control of phytoplankton photosynthesis in the Western North Atlantic. Nature 356: 229-231

Platt T, Broomhead DS, Sathyendranath S, Edwards AM, Murphy EJ (2003) Phytoplankton biomass and residual nitrate in the pelagic ecosystem. Proc R Soc Lond Ser A 459:1063-1073. DOI: 10.1098/rspa.2002.1079

Sakshaug E, Slagstad D, Holm-Hansen O (1991) Factors controlling the development of phytoplankton blooms in the Antarctic Ocean-a mathematical model. Mar Chem 35: $259-271$

Steele JH, Henderson EW (1992) The role of predation in plankton models. J Plankton Res 14:157-172

Submitted: September 12, 2002; Accepted: December 19, 2002 Proofs received from author(s): May 15, 2003 